\title{
Trigeminal perineural spread of renal cell carcinoma
}

\section{Propagação perineural trigeminal do carcinoma de células renais}

Alejandro Hornik', Jordan Rosenblum², José Biller ${ }^{3}$

A 55-year-old man had a five-day history of "pins and needles" sensation on the left chin. Examination showed decreased pinprick sensation on the territory of the left mandibular branch of the trigeminal nerve. Brain magnetic resonance imaging (MRI) with gadolinium showed enhancement involving the left mandibular branch (Fig 1). Computed tomography (CT) of the chest, abdomen, and pelvis showed a left kidney mass (Fig 2) diagnosed as renal carcinoma following nephrectomy.

The "numb-chin" syndrome heralds or accompanies systemic malignancies ${ }^{1}$. Trigeminal perineural spread has been well-documented in head and neck neoplasms ${ }^{2}$, however, to our knowledge, it has not been reported in renal neoplasms.
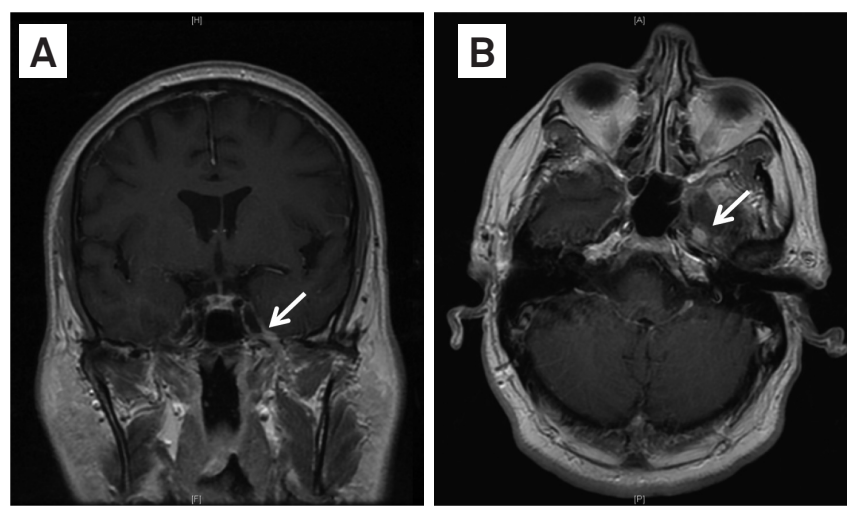

Fig 1. Magnetic resonance imaging of the brain (T1W) with gadolinium, coronal (A), and axial (B) shows an asymmetrically enlarged enhancing mandibular branch of the left trigeminal nerve at the level of the foramen ovale and masticatory space (arrow). There was no bony erosion on the computed tomography scan (not shown).
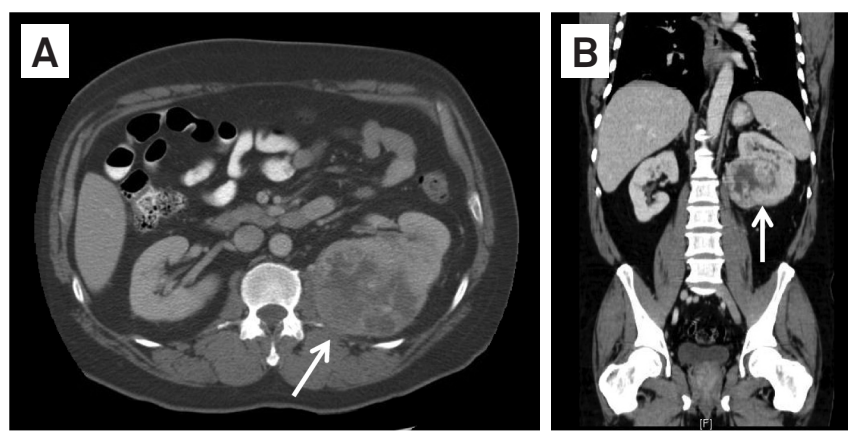

Fig 2. Computed tomography of the chest, abdomen, and pelvis with contrast, axial (A), and coronal reconstruction (B) shows an exophytic peripheral enhancing mass (arrow) arising from the posterior interpolar aspect of the left kidney.

\section{References}

1. Lossos A, Siegal T. Numb chin syndrome in cancer patients: etiology, response to treatment, and prognostic significance. Neurology 1992;42:1181.
2.

Warden KF, Parmar H, Trobe JD. Perineural spread of cancer along the three trigeminal divisions. J Neuro-Ophthalmology 2009;29: 300-307.

\footnotetext{
'Department of Neurology, Chief Resident, Stritch School of Medicine, Loyola University Medical Center, Chicago, USA;

2Department of Radiology, Director Neuro-Radiology, Stritch School of Medicine, Loyola University Medical Center, Chicago, USA; ${ }^{3}$ Department of Neurology, Chairman, Stritch School of Medicine, Loyola University Medical Center, Chicago, USA.

Correspondence: José Biller; Department of Neurology, Loyola University Chicago, Stritch School of Medicine; 2160 S. 1 st Avenue / Bldg. 105, Room 2700; Maywood, IL 60153 - E-mail: jbiller@lumc.edu

Conflict of interest: There is no conflict of interest to declare.

Received 01 March 2012; Received in final form 30 April 2012; Accepted 07 May 2012
} 